\title{
A poética da entrevista no documentário O país de São Saruê
}

\section{Poetics of the interview in the documentary $O$ país de São Saruê}

José Francisco Serafim ${ }^{1}$, Renato Meira dos Santos Filho 


\section{Resumo}

O presente artigo discorre sobre questões poéticas e retóricas envolvendo o documentário O país de São Saruê, dirigido pelo cineasta paraibano Vladimir Carvalho, concluído originalmente em 1971. Adotando noções de "poética da entrevista no filme documentário", como sugeridas por Leger Grindon (2007), esta análise tem como interesse maior a compreensão de como a construção das entrevistas contribui para a estrutura argumentativa dessa obra. Observamos que, na composição das entrevistas, o realizador se utiliza de técnicas cinematográficas que tendem à redução da polivalência do conjunto de falas dos entrevistados, ainda que uma variedade de opiniões, por vezes conflitantes, atravesse o filme.

\section{Palavras-chave}

O país de São Saruê, poética da entrevista, cinema documentário.

\section{Abstract}

This paper discusses poetical and rethorical aspects regarding the Brazilian documentary film O País de São Saruê, directed by Vladimir Carvalho, and completed in 1971. Approaching the object through the "poetics of the documentary film Interview", as proposed by Leger Grindon (2007), our analisys sought to better explore how the way interviews are contributes to the structure of the arguments supported throughout the film. We found that, although the documentary was permeated by diverse, even conflicting opinions, the way the interviews were conducted tends to decrease the versatility present in the statements collected by the filmmaker.

\section{Keywords}

O País de São Saruê, poetics of the interview, documentary cinema. 
A luta para sobreviver à miséria é assunto que comumente acompanha as representações midiáticas do sertão nordestino. Desde as coberturas jornalísticas nacionais até a arte tradicional da própria região (seja na forma de canções, romances ou dos típicos folhetos de cordel), são frequentes os temas da seca, do cangaço e o retrato do semiárido como uma terra necessitada e de gente devota - um povo que, frente à realidade difícil, busca consolo na fé e em profecias sebastianistas de um futuro mais próspero. O semiárido nordestino é, em conjunto talvez com as imagens das favelas e dos povos ribeirinhos, um dos elementos mais marcantes para a constituição do imaginário de subdesenvolvimento do país. Consequentemente, mesmo no audiovisual documental, são muitas as produções que reproduzem os estereótipos desse sertão convencionado.

Há, todavia, obras em cujo discurso se apresenta a recusa à naturalização da pobreza sertaneja, como é o documentário O país de São Saruê (1971/2004)3. Dirigido pelo cineasta paraibano Vladimir Carvalho, o filme trata o subdesenvolvimento como uma problemática que ultrapassa o clima local e como crítica ao abandono estatal. Enquadra o semiárido pelos bens que o povo dessa região produz, sugerindo que, mais do que a seca, são as desiguais estruturas socioeconômicas historicamente dominantes no Brasil que levam ao subdesenvolvimento do sertão.

Lançado durante o truculento governo de Garrastazu Médici, O país de São Saruê (1971/2004) foi sumariamente censurado por causa dessa retórica de denúncia da exploração econômica, de valorização do trabalho e de partilha de riquezas - como nota a historiadora Shirly Souza (2010, p. 65-66), em dissertação na qual analisou pareceres dos órgãos de censura sobre o documentário. A liberação para circulação veio somente em 1978, quando a censura decidiu que foi interditado pelos órgãos de censura do regime militar, fato que dificultou a devida preservação da obra. Os rolos originais, de $16 \mathrm{~mm}$, foram perdidos, e a única versão atualmente disponível do filme é produto de uma restauração finalizada em 2004, a partir de cópias ampliadas para $35 \mathrm{~mm}$. Segundo informações presentes dentre os créditos de abertura desta versão, algumas cenas jamais recuperaram sua qualidade ótica original. Creditamos aqui o filme nas duas datas com o objetivo de marcá-lo em seu momento histórico adequado, mas também para reconhecer as alterações pelas quais a versão que tivemos acesso pode ter passado. 
as mensagens do filme já teriam perdido a força política, a chamada "técnica de esfriamento" (SOUZA, 2010, p. 68).

Atualmente, esse contexto político da distribuição quase inevitavelmente precede a apreciação do documentário, uma vez que a única versão atualmente disponível traz, logo nos primeiros segundos, intertítulos sobre a interdição do filme e sobre o processo de restauração pelo qual passou em 2004, sob a supervisão de Vladimir Carvalho. Dessa forma, muito do discurso que atravessa o documentário parece atentar para questões contextuais. Mesmo o que é escrito academicamente carrega interesses na história, com foco no tema da censura, ou tratando da representação da memória local (ver FEITOSA, 2014a, 2014b; MOURA, 1996; SOUZA, 2010). A sobrevivência deste filme é, por um lado, uma bandeira contra a opressão; por outro, patrimônio da herança sertaneja.

Ao comentar uma matéria de jornal que descrevia o acolhimento caloroso que o filme recebeu após sua liberação, Shirly Souza nota o quão comum é a importância atribuída a este documentário, que se deve "mais ao fato de ele ter sido censurado que às características estéticas do filme propriamente ditas" (SOUZA, 2010, p. 75). Nesta análise, preenchendo uma aparente lacuna nos debates sobre O país de São Saruê (1971/2004), daremos maior atenção à materialidade da obra, investigando a influência que as entrevistas tiveram sobre o discurso político do documentário. Foco analítico traduzido na seguinte questão: "Como a poética das entrevistas de O país de São Saruê (1971/2004) contribuiu para o discurso político do filme?". Buscaremos respostas com referência maior nas concepções do teórico Leger Grindon (2007) acerca daquilo que chama de "poética da entrevista do filme documentário". Apoio complementar será trazido com base em Bill Nichols (1991, 2010), Julio Wainer (2014), Christina Ferraz Musse e Mariana Ferraz Musse (2010).

\section{Entrevistas no cinema documentário}

As primeiras tentativas de realizar entrevistas em documentários surgiram ainda nos primeiros anos do cinema com som, na década de 1930. Na tese intitulada 
A entrevista no documentário, Julio Wainer (2014, p. 15) cita as experiências nos filmes Housing problems (1935), de Edgar Anstey e Arthur Elton (em equipe liderada por John Grierson), e Entuziazm (1930), de Dziga Vertov, como precursoras da entrevista no cinema. Entretanto, o maquinário da época limitava as locações, e o trabalho de sincronização era difícil (WAINER, 2014, p. 15). Por conseguinte, a captação do real nos documentários do período inicial do cinema era sustentada principalmente pela imagem.

Não apenas as questões técnicas, mas também os modos de pensar o cinema mantinham os primeiros documentários centrados na visualidade. É importante lembrar que, nas suas origens, o que o meio cinematográfico trazia como inovação era precisamente a captura do movimento, do visual através do tempo. A princípio, eram as implicações acerca das possibilidades de ver o real através da câmera/montagem que mais chamavam a atenção dos realizadores e intelectuais. Cinematografia, como o nome sugere, nasce simplesmente como a grafia daquilo que é cinético.

No artigo Q\&A: poetics of the documentary film interview ${ }^{4}$, o pesquisador Leger Grindon (2007, p. 4) afirma que a proeminência da entrevista nos documentários se torna comum entre as décadas de 1950 e 1960. Fenômeno impulsionado por mudanças técnicas, como o desenvolvimento de equipamentos de som sincronizado (som direto) portáteis e novas elaborações conceituais, com a formação das correntes artísticas do cinema verdade e cinema direto.

Autores do cinema direto privilegiavam a não interação como forma de alcançar algo próximo da realidade. Em filmes como Primary (1960), de Robert Drew, os realizadores tentavam assistir sem intervir no desenrolar dos acontecimentos. Os equipamentos pequenos eram usados, no cinema direto, pela sua discrição. Já os diretores alinhados ao cinema verdade utilizavam a portabilidade como ferramenta de aproximação e intervenção. Acreditavam ser impossível a passividade e buscavam maior engajamento com a realidade (GRINDON, 2007, p. 4-5), como em 
Crônica de um verão (1961), de Edgar Morin e Jean Rouch. De maneiras distintas, ambas as escolas buscavam maior autenticidade na representação documental.

Grindon (2007) comenta que, no decorrer do século XX, documentaristas passaram a demonstrar certa "suspeita frente à informação visual" (GRINDON, 2007, p. 5, tradução nossa) ${ }^{5}$, construindo filmes crescentemente baseados nos testemunhos, em detrimento das imagens de arquivos e registros históricos. A voz no documentário, que costumava tomar a forma da voz de deus (narração expositiva), deu lugar à voz dos próprios atores sociais ${ }^{6}$ retratados. No artigo $A$ entrevista no telejornalismo e no documentário: possibilidades e limitações, Christina Musse e Mariana Musse afirmam que "nessa nova relação tem voz quem é documentado, e essa voz é captada geralmente através da entrevista, um dos principais métodos de abordagem no documentário contemporâneo" (MUSSE; MUSSE, 2010, p. 6).

Como pontua Julio Wainer (2014), a evolução da história do documentário parece ser marcada pela vontade "de que o personagem fale diretamente ao espectador, com o mínimo de intermediação possível" (WAINER, 2014, p. 30). A ponto de a definição do que é uma entrevista se confundir com depoimento ou mesmo narração, de tão recorrente que é a tentativa de se apagar a pessoa do entrevistador. Musse e Musse (2010) pontuam que "há cada vez mais a presença dos depoimentos, captados através de entrevistas em que o entrevistador pode ou não aparecer" (2010, p. 7). Contudo, mesmo que perguntas não estejam explícitas no filme, ainda podemos tratar dos depoimentos como entrevista, pois como afirma Wainer: "Se alguém é convidado a participar de um filme e em algum momento ele se manifesta com a fala, é porque algo Ihe é perguntado, ou proposto" (2014, p. 31).

Caso não fique claro se num certo filme as entrevistas foram captadas diretamente, se são material de arquivo ou até encenadas, dados sobre a produção

$5 \quad$ "Suspicion of visual information" (GRINDON, 2007, p. 5).

$6 \quad$ O termo "ator social" é uma forma de se dirigir às pessoas representadas em um documentário. Não como atores ou personagens, mas sim lembrando que são indivíduos que tem vidas próprias para além do filme, como nota Bill Nichols (2010, p. 31). 
podem ajudar a resolver as dúvidas. Em O País de São Saruê (1971/2004), por exemplo, nenhuma das entrevistas foi feita em câmera. Souza (2010) afirma que elas aconteceram em "estúdios de rádios ou de difusoras de alto-falantes [...] o que Vladimir Carvalho chamou de 'técnica do som indireto'" (SOUZA, 2010, p. 30). Apesar de não estar munido dos equipamentos portáteis que popularizaram o cinema de som direto, Carvalho buscou os meios possíveis para transmitir a sensação de captura espontânea da voz dos atores sociais. Na montagem, sobrepôs vozes às imagens de quem fala, e adicionou ruídos para simular os ambientes captados.

Outra evolução que é preciso mencionar sobre a inserção da entrevista no documentário é o fato de que, em meados do século $X X$, o telejornalismo estava nascendo e aperfeiçoando o uso da entrevista no audiovisual (GRINDON, 2007, p. 4; WAUGH, 2011, p. 130). Não é possível quantificar o que o cinema absorveu da TV ou vice-versa, mas é aparente que há trocas entre os dois meios. É bastante comum, inclusive, que jornalistas façam documentários para cinema (como o próprio Vladimir Carvalho, que tinha experiência em rádio e jornal), ou que cineastas trabalhem no jornalismo televisivo (como é o caso de Eduardo Coutinho, que por anos atuou no programa Globo Repórter ${ }^{7}$ ). Padrões de apuração, imparcialidade e credibilidade, como consolidados no jornalismo, começaram a ser preocupação dos documentaristas, e o conteúdo factual do testemunho ganhou importância na relação com o estilo cinematográfico. Como Grindon nota, "muitos documentários contemporâneos são pouco mais que entrevistas e material compilado" (2007, p. 4, tradução nossa) ${ }^{8}$.

\section{A poética da entrevista}

Entendendo a relevância que tem a consolidação da entrevista no documentário, alguns teóricos buscaram estratégias que auxiliassem em sua investigação. 
Com destaque, Bill Nichols (1991) propôs quatro classes diferentes de entrevista. Da mais participativa àquela na qual o realizador exerceria maior controle, o autor as chamou de: conversa, entrevista mascarada, pseudodiálogo e entrevista comum (NICHOLS, 1991, p. 51-53, tradução nossa) ${ }^{9}$. Contudo, segundo Leger Grindon (2007, p. 6), essa classificação não seria bastante efetiva, por tomar a participação dos atores sociais como determinante e por não levar em consideração as práticas de produção que não transparecem tão facilmente no filme.

Grindon (2007) concebe uma abordagem que, diferentemente da proposta por Nichols (1991), não sugere tipos possíveis de entrevista, mas categorias de análise, para as quais se deve olhar levando em conta contextos históricos e práticas autorais, a fim compreender como a relação imagem/som criada na obra comunica (GRINDON, 2007, p. 6). O autor propõe cinco categorias: "presença, perspectiva, contexto pictórico, performance, e polivalência" (GRINDON, 2007, p. 6, tradução nossa) $)^{10}$.

A primeira categoria, a presença, diz respeito à representação do processo de entrevista, se nele o realizador deixa evidente a dinâmica de perguntas e respostas (GRINDON, 2007, p. 7). Uma entrevista na qual as perguntas ficam explícitas pode transmitir um tom mais forte de diálogo espontâneo, permitir o conflito de opiniões e a exposição da intervenção do realizador. Já depoimentos isolados possibilitam, por exemplo, conferir maior valor de verdade às afirmações dos atores sociais, pois não há refutação por parte do entrevistador. Em $O$ país de São Saruê (1971/2004), a presença de Vladimir Carvalho é um aspecto que varia no decorrer da obra. Frente a certos entrevistados, o diretor se mostra mais combativo, enquanto permite que outros falem sem interrupção, sugerindo apoio a alguns discursos e discordância com os demais.

A segunda categoria, referente à perspectiva, volta a atenção para o posicionamento da câmera durante as entrevistas. Proximidade pode transmitir 
intimidade ou intensidade (GRINDON, 2007, p. 7), já distância pode, por exemplo, direcionar o foco para o ambiente. No documentário de Carvalho, porém, não são expostas perspectivas do momento das entrevistas. Há apenas o registro do áudio dos relatos e um trabalho de montagem que tenta simular o estilo do som sincronizado.

A terceira categoria, o contexto pictórico, "refere-se às imagens independentes que complementam ou trabalham como contraponto ao testemunho verbal de quem fala" (GRINDON, 2007, p. 7, tradução nossa) ${ }^{11}$. É a montagem de imagens e sons capturados fora do momento da entrevista, é também a alternância entre múltiplos relatos. Por meio desse contexto, "o cineasta pode oferecer uma informação crucial capaz de mudar nossa atitude em relação ao sujeito" (GRINDON, 2007, p. 7, tradução nossa) ${ }^{12}$. Inclui imagens de arquivo, músicas ou qualquer material de apoio.

Notamos que a abordagem de Grindon (2007) implicaria enquadrarmos todas as imagens d'O país de São Saruê (1971/2004) pela via do contexto pictórico, visto que não há registro visual das entrevistas. No entanto, frente às particularidades do "som indireto", acreditamos não ser o mais adequado que a categoria da perspectiva ou, até certo ponto, mesmo a da performance (que veremos a seguir) sejam ignoradas. Apesar de imagens e relatos serem, a rigor, separados, a montagem constantemente incentiva sua fusão. Logo, ainda que não exista filmagem dos testemunhos, podemos considerar aspectos da perspectiva nos trechos que acompanham as vozes.

$\mathrm{Na}$ quarta categoria, temos a performance, que informa o comportamento dos atores sociais, sua naturalidade, que expressões fazem, como estão vestidos (GRINDON, 2007, p. 7). Na descrição dada por Grindon (2007, p. 7), a performance aparece com foco na visualidade; contudo, entendemos que a voz do testemunho não é somente portadora de conteúdo, nela há também performance. 
Linguajar, tom, pausas etc. podem caracterizar tanto quanto indumentária ou linguagem corporal - particularmente em um filme como o que analisamos.

Em O país de São Saruê (1971/2004), um patrão é mostrado caminhando entre os seus funcionários maltrapilhos, um prefeito atende cidadãos necessitados, e ambos falam com a eloquência de figuras públicas, em contraste com os erros de concordância dos mineradores pobres. As performances dos entrevistados são notavelmente utilizadas pelo realizador como ferramenta do seu discurso sobre o sertão. Entretanto, Nichols (2010) comenta que esse tipo de ajuste do comportamento em função da câmera é um ponto delicado em documentários, pois pode "se tornar uma forma de deturpação, ou distorção, em um sentido, mas também documentam como o ato de filmar altera a realidade" (NICHOLS, 2010, p. 31).

Por fim, a quinta categoria, chamada polivalência, é "distinta das outras quatro porque ao invés de ser um aspecto do design da entrevista, emerge como resultado do todo" (GRINDON, 2007, p. 8, tradução nossa) ${ }^{13}$. Ela informa se as entrevistas, tomadas em conjunto, articulam um argumento unificado, ou se elas fazem emergir conflitos e tensões sobre o tema (GRINDON, 2007, p. 8). Seria a busca pelas conclusões às quais o filme chega, visto que o documentarista não faz mera observação descritiva da realidade, mas uma construção discursiva, na qual elementos como narrativa, poética e lógica "são utilizados para nos convencer de um assunto para o qual é possível mais de um ponto de vista ou conclusão" (NICHOLS, 2010, p. 44) - especialmente em um filme de teor político como O país de São Saruê (1971/2004). Nesse processo, tem centralidade o relato pessoal. Comenta Hudson Moura que: "A memória oral é o maior trunfo dos documentários, eles dão maior credibilidade ao registro quanto mais eloquente for o testemunho" (1997, p. 2).

Enquanto o cinema ficcional pede que suspendamos nossa descrença, o documental pede que creiamos não somente na fidelidade das representações, mas também na validade das conclusões. Para Nichols (2010), a natureza investigativa 
do documentário costuma levar a uma "solução conclusiva, que o espectador é estimulado a endossar ou adotar como sua" (NICHOLS, 2010, p. 54). Aqui, com apoio da poética de Grindon (2007), buscamos indícios dessa construção retórica nas entrevistas d'O país de São Saruê (1971/2004).

\section{Entrevistas de 0 país de São Saruê}

Letreiros informativos abrem o documentário, apresentando as localidades filmadas (vale do rio do Peixe e vale do rio Piranhas, na Paraíba), comentando sobre a desigualdade social da região e trazendo uma dedicatória aos sertanejos que colaboraram com a produção da obra. O texto se dirige a eles por suas profissões (lavradores, vaqueiros, tangerinos etc.) e os agradece pelo fato de terem aberto mão de horas de trabalho para possibilitarem as gravações. Esses intertítulos deixam claras duas das principais características do documentário: o foco na luta histórica do trabalhador e a intenção metonímica do discurso. Não importa quem são, em nome, os trabalhadores que recebem dedicatória; importa o que são, enquanto grupo, sertanejos.

Dessa introdução, o filme segue para as representações do trabalho no campo, acompanhando especialmente a pecuária, a colheita do algodão e a mineração. Textos anteriores (como FEITOSA, 2014a, 2014b; SOUZA, 2010) sugerem tratarmos os segmentos nos quais cada uma dessas três atividades econômicas é retratada quase como atos do filme. Shirly Souza (2010) chama estes blocos de "ciclos do gado, do algodão e do minério" (SOUZA, 2010, p. 45), enquanto o historiador André Feitosa fala de "mundos" (FEITOSA, 2014b, p. 21). Grosso modo, podemos considerar que o ciclo do gado se refere ao primeiro terço da obra, o ciclo do algodão aos vinte minutos seguintes e o ciclo do minério aos quase trinta minutos restantes.

O ciclo do gado não contém entrevistas, cabendo aqui apenas breve descrição. É o ato da obra no qual têm maior destaque a poesia e a narração expositiva. A narração conta fatos da história local e relaciona o trabalho duro da pecuária com o folclore, mostrando como a dificuldade é apropriada como 
matriz da cultura. A rima trata também do passado, com versos que mencionam a presença original de povos indígenas na região e falam da chegada dos colonos, destacando sua determinação em prosperar naquela terra. O tom é de nostalgia, e o tema da ruína parece ter proeminência. A sede de uma fazenda aparece abandonada pelos donos, e os festejos tradicionais, conta a narração, são cada vez menos praticados.

Segue-se então para o ciclo do algodão, que se inicia acompanhando uma família de cotonicultores. A narração descreve o injusto sistema de meação sob o qual trabalham, explicando que dele se beneficiam os latifundiários, industrialistas e banqueiros às custas dos lavradores. Então, a família de camponeses é mostrada carregando o algodão até o local da partilha, em uma sequência muito reminiscente do documentário Aruanda (Linduarte Noronha, 1960, no qual Vladimir Carvalho trabalhou como assistente ${ }^{14}$. Essa é a deixa para a primeira entrevista do filme, com José Gadêlha, parlamentar e dono de uma usina de algodão.

\section{Entrevistas do ciclo do algodão}

Antes de sua entrevista, a narração sugere ser Gadêlha um vassalo da indústria internacional - homem rico da região, que ainda que explore a produção dos trabalhadores locais, vê seu negócio perder espaço para empresas de fora (o tema da ruína local permanece). Então, a voz de Vladimir Carvalho abre a entrevista, com uma pergunta feita diretamente ao usineiro acerca de sua família. Enquanto José Gadêlha fala de sua linhagem, a montagem contrasta seu carro de luxo com as sacas de algodão colhidas por camponeses.

A presença do entrevistador é estabelecida de início, e ainda que a troca flua com certa naturalidade, é Carvalho que direciona a conversa, extraindo informações precisas. Gadêlha, em performance certamente facilitada pelo 
realizador, caminha bem-vestido por entre seus funcionários, como que supervisionando-os. Sobre essas imagens, Carvalho pergunta o que Gadêlha pensa sobre a situação do sertanejo. O usineiro responde culpando os bancos e o abandono do governo pela miséria.

O entrevistador, então, em provável tentativa de provocar Gadêlha, pergunta ao parlamentar se tinha experiência com o trabalho camponês. Ele logo replica, falando já ter limpado seu próprio roçado, trabalhado na lavoura (não por diletantismo, acrescenta, mas por necessidade). Reforçando, por fim, que: "não há salvação para a gente do nordeste [...] se não houver ajuda do governo" (O PAÍS..., 1971/2004). Ao longo dessa fala, planos de operários são justapostos às imagens de Gadêlha que, em contraste quase cômico, embarca numa pequena aeronave e, acenando janela a fora, voa para longe.

A maneira como Carvalho dirige a entrevista aponta um esforço de descreditar a posição do entrevistado. Evitando conflito aberto, o realizador compõe um trecho que - em termos de presença, perspectiva, contexto pictórico e performance - sugere que a pobreza do sertanejo é perpetuada não por falta de caridade, mas pelas práticas comerciais de empresários como o próprio Gadêlha. Essa posição de crítica ao assistencialismo é fortalecida, na segunda entrevista do filme, dada por Charles Foster, integrante do Peace Corps ${ }^{15}$ estadunidense.

Precede a entrevista com Foster uma sequência que enfatiza a assimilação da cultura estadunidense. Em uma feira tradicional, pessoas tiram seus calçados de couro para experimentar chinelos de borracha, um cartaz da Coca-Cola é enquadrado acima de homens de gibão etc. Nesse trecho, retorna o uso da poesia sobre o sertão; entretanto, dessa vez, a rima é sobreposta com a canção Quero que vá tudo pro inferno, interpretada por Roberto Carlos. Charles Foster então se apresenta, ao som de Era um garoto que como eu amava os Beatles 
e os Rolling Stones, d'Os Incríveis ${ }^{16}$, música que fala de um jovem americano forçado a ir para a guerra do Vietnã.

A entrevista começa como um depoimento, sem intervenção de Carvalho. O jovem voluntário do Corpo da Paz explica estar no Nordeste para ajudar a implementar iniciativas de ação comunitária. Foster é filmado andando por entre sertanejos, cumprimentando alguns, parando para conversar com outros. É mostrado como uma figura pública, e afirma ter conversas frequentes com os moradores, buscando soluções para os problemas da comunidade.

As imagens de Foster são então interrompidas por um recorte de jornal no qual se pode ler: "Voluntários da Paz do Nordeste protestam contra convocação para Veitname [sic]" (O PAÍS..., 1971/2004). É nesse momento que Carvalho decide fazer-se presente na entrevista. O diretor pergunta a que Foster credita o grande atraso do Brasil. O voluntário hesita e diz não poder responder a essa dúvida. Imediatamente, Carvalho pergunta sua opinião sobre a guerra no Vietnã (retorna à tela o recorte de jornal). Sobre esta imagem, Foster diz: "Não posso responder. Porque não sei bastante sobre guerra lá no Vietnã" (O PAÍS..., 1971/2004).

Nessa entrevista, o realizador novamente articula elementos que contradizem o entrevistado. O depoimento que o rapaz faz inicialmente sobre si o mostra como um agente político, vindo ao Brasil para trazer soluções. Contudo, a montagem, o texto escrito e a interrupção feita pelo realizador sugerem a ignorância do estrangeiro frente não somente aos problemas brasileiros, mas também a questões políticas do seu país de origem. Se o ciclo do gado serviu como introdução, o ciclo do algodão tem a função de refutar os argumentos que normalizam o subdesenvolvimento nordestino. O abandono estatal é enquadrado como bode expiatório das elites, e a ajuda americana como porta de entrada para a sua indústria. 


\section{Entrevistas do ciclo do minério}

Este segmento se inicia com uma narração sobre a descoberta de ouro na região. Seguem as entrevistas com Pedro Alma, um antigo pioneiro do ouro, e Zeca Inocêncio, um ex-garimpeiro. As duas entrevistas são apresentadas em sequência, sem interrupção por narração, música ou poesia. Alma relata a prosperidade de outrora e lamenta a ruína da indústria de mineração da região. Da mesma forma, Inocêncio fala sobre as minas e a riqueza que jaz intocada sob o solo sertanejo.

Ao longo das falas desses homens, Carvalho apenas faz perguntas de esclarecimento. "O que é bodega?", pergunta a Inocêncio; "quantos anos o senhor tem?", a Alma (O PAÍS..., 1971/2004). No mais, questiona a razão de as minas não existirem mais, ao que ambos respondem dizendo não haver licenças do governo. As intervenções de Carvalho neste trecho não incluem réplicas, como nos casos anteriores. O entrevistador os deixa falar com liberdade e constrói um contexto pictórico que em momento algum contraria o que dizem. Pelo contrário, a montagem reforça os discursos dos mineradores, mostrando situações de pobreza, prédios em ruínas. Alma e Inocêncio trazem discursos com os quais, ao que indica a composição das entrevistas, o filme concorda. Exemplificam vidas que parecem apenas piorar, diferentemente do otimismo que Charles Foster apresentava.

O filme segue, dessa forma, para a última entrevista, apresentando o depoimento com o qual parece mais concordar, dado por Antônio Mariz, o então prefeito da cidade paraibana de Sousa e principal apoiador da produção do documentário. Depois de breves planos que enquadram o prefeito sentado sob uma fotografia de Getúlio Vargas, Mariz inicia um monólogo que dura aproximadamente seis minutos, sem que Carvalho o interrompa. A presença do cineasta é nula neste trecho.

A Mariz é dada a autoridade sobre a conclusão da obra. Como se assumisse o lugar da "voz de deus", ele segue em um discurso expositivo no qual defende os sertanejos e afirma que a pobreza é "fruto de longos erros acumulados na forma de explorar a terra" (O PAÍS..., 1971/2004). Ele nega que sejam as condições do clima que perpetuem a miséria, dizendo que o povo sertanejo é capaz de superar 
esses problemas menores "para estabelecer uma sociedade próspera, uma terra rica, em cuja riqueza participem todos" (O PAÍS..., 1971/2004). Carvalho encerra seu documentário com falas nas quais Mariz consolida o discurso político da obra. Encenação, fotos de arquivos e planos de apoio complementam sua fala.

\section{Considerações finais}

O país de São Saruê (1971/2004) é uma obra sobre a memória sertaneja. Não somente no sentido de ser um registro da vida local em determinado momento, mas também, e talvez principalmente, porque é um filme que pauta os conflitos que atravessam a memória coletiva e o imaginário do sertão. Como nota Moura (1997), "as memórias estão em todas as imagens que [Vladimir Carvalho] capta e revive, mas com o olhar do presente" (MOURA, 1997, p. 5). Já Christine Santos (2006) afirma que as obras do diretor se inserem em "um processo de interpretação do momento histórico à luz de convicções apresentadas sob a estética artesanal dos próprios filmes" (SANTOS, 2006, p. 20). Recorrendo aos relatos de variadas testemunhas da história recente, o que Carvalho faz em O país de São Saruê (1971/2004) é convocar estes atores sociais a recuperarem em suas memórias, em suas representações do passado, causas ou explicações para os problemas do sertão.

Desse modo, o filme colhe opiniões diversas e, por vezes, contrastantes sobre o subdesenvolvimento e possíveis soluções. Gadêlha, por exemplo, culpa a falta de assistência do governo, já Mariz fala em reforma agrária. Dada essa diversidade de ideias, porém, seria de se esperar que a apreciação suscitasse alguma polivalência, ou diferentes leituras da situação aos olhos dos espectadores. Entretanto, a maneira como o documentário foi composto permite poucas deixas para a interpretação. O discurso da obra se atém sempre ao projeto político de apoio aos trabalhadores sertanejos, frente a um cenário de ditadura, imperialismo econômico e distribuição desigual da terra e de proventos.

A posição assumida desde o princípio do filme é de negação da naturalização da miséria e da desculpa da inevitabilidade da seca. Portanto, quando opiniões 
destoantes são expostas, logo são enquadradas pelo realizador. O esforço retórico do documentário, a contribuição que tenta fazer para a memória e o imaginário sertanejo, está em rejeitar velhos bodes expiatórios e destacar os sistemas econômicos que perpetuam a pobreza. Para tal, o conjunto de relatos do filme tem sua potencial polivalência reduzida, ao passo que o realizador usa da linguagem cinematográfica para comentar os relatos verbais, impedindo que discursos como os de Gadêlha e Foster sejam aceitos como resposta final aos problemas do sertão. Contudo, Carvalho jamais explicita suas discordâncias diretamente aos entrevistados, o que, de uma perspectiva ética, poderia negar-lhes a oportunidade de réplica, de defesa de seus argumentos ou de desenvolvimento da complexidade da questão.

Neste trabalho, o uso da poética da entrevista (GRINDON, 2007) mostrou-se estratégia muito adequada para que pudéssemos analisar com mais detalhe a relação ator social/documentarista, e para nos aproximarmos do caminho retórico que O país de São Saruê (1971/2004) percorre. Contudo, consideradas as particularidades do filme que analisamos, nota-se que há espaço para ajustes no modelo, em especial, na forma como delimita o contexto pictórico e a performance.

\section{Referências}

FEITOSA, A. F. A estética como conteúdo histórico: a terra e o homem em O país de São Saruê. In: ENCONTRO ESTADUAL DE HISTÓRIA, 16., 2014, Campina Grande. Anais [...]. Campina Grande: ANPUH-PB, 2014a. Disponível em: https://bit.ly/34c3uXX. Acesso em: 12 abr. 2020.

FEITOSA, A. F. Documentário e cultura histórica: o sertão de trabalho e relações de classe em O País de São Saruê (1971). 2014. Dissertação (Mestrado em História) - Universidade Federal da Paraíba, João Pessoa, 2014b. Disponível em: https://bit.ly/2STaNkD. Acesso em: 12 abr. 2020. 
GRINDON, L. Q\&A: poetics of the documentary film interview. The Velvet Light Trap, Austin, n. 60, p. 4-12, 2007. Disponível em: https://bit.ly/3oEbnPe. Acesso em: 8 mar. 2020.

MOURA, H. C. Memória \& exílio: o cinema de Vladimir Carvalho. 1996. Dissertação (Mestrado em Comunicação) - Pontifícia Universidade Católica de São Paulo, São Paulo, 1996. Disponível em: https://bit.ly/3hKe40h. Acesso em: 10 abr. 2020.

MOURA, H. C. Oralidade e fabulação no cinema documentário. São Paulo: Pontifícia Universidade Católica de São Paulo, 1997. Disponível em: https://bit.ly/3tWAxcM. Acesso em: 8 jan. 2021.

MUSSE, C. F.; MUSSE, M. F. A entrevista no telejornalismo e no documentário: possibilidades e limitações. RuMoRes, São Paulo, v. 4, n. 8, 2010. Disponível em: https://bit.ly/3bDv4Bt. Acesso em: 27 mar. 2020.

NICHOLS, B. Introdução ao documentário. 5. ed. Tradução de Mônica Saddy Martins. Campinas: Papirus, 2010.

NICHOLS, B. Representing reality: Issues and concepts in documentary. Bloomington: Indiana University Press, 1991.

O PAÍS de São Saruê. Direção: Vladimir Carvalho. Produção: Vladimir Carvalho e João Ramiro Mello. Edição: Eduardo Leone. Fotografia: Manuel Clemente. Voz do poema: Echio Reis. Voz da narração: Paulo Pontes. Entrevistados: José Gadêlha, Charles Foster, Antônio Mariz, Pedro Alma e Zeca Inocêncio. Brasil: Embrafilme, 2004. 1 DVD (80 $\mathrm{min})$.

SANTOS, C. V. Vladimir Carvalho: do popular ao público: O homem de areia e O evangelho segundo Teotônio. 2006. Dissertação (Mestrado em Multimeios) - 
Universidade Estadual de Campinas, Campinas, 2006. Disponível em: https://bit. ly/3u0SvuH. Acesso em: 20 jan. 2021.

SOUZA, S. F. O sertão como dado, São Saruê como aspiração: o documentário O país de São Saruê entre a utopia e a política. 2010. Dissertação (Mestrado em História) - Universidade Estadual de Campinas, Campinas, 2010. Disponível em: https://bit.ly/2RoUxIO. Acesso em: 8 mar. 2020.

WAINER, J. A entrevista no documentário. 2014. Tese (Doutorado em Comunicação) Pontifícia Universidade Católica de São Paulo, São Paulo, 2014. Disponível em: https://bit.ly/3bEr5oc. Acesso em: 12 mar. 2020.

WAUGH, T. The right to play oneself: looking back on documentary film. Minneapolis: University of Minnesota Press, 2011.

submetido em: 4 ago. 2020 | aprovado em: 9 mar. 2021 